\title{
BIODEGRADABLE SYNTHETIC POLYMERS FOR TISSUE ENGINEERING
}

\author{
Pathiraja A.Gunatillake and Raju Adhikari \\ CSIRO Molecular Science, Bag 10, Clayton South MDC, Vic 3169, Australia
}

\begin{abstract}
This paper reviews biodegradable synthetic polymers focusing on their potential in tissue engineering applications. The major classes of polymers are briefly discussed with regard to synthesis, properties and biodegradability, and known degradation modes and products are indicated based on studies reported in the literature. A vast majority of biodegradable polymers studied belongs to the polyester family, which includes polyglycolides and polylactides. Some disadvantages of these polymers in tissue engineering applications are their poor biocompatibility, release of acidic degradation products, poor processability and loss of mechanical properties very early during degradation. Other degradable polymers such as polyorthoesters, polyanhydrides, polyphosphazenes, and polyurethanes are also discussed and their advantages and disadvantages summarised. With advancements in tissue engineering it has become necessary to develop polymers that meet more demanding requirements. Recent work has focused on developing injectable polymer compositions based on poly (propylene fumarate) and poly (anhydrides) to meet these requirements in orthopaedic tissue engineering. Polyurethanes have received recent attention for development of degradable polymers because of their great potential in tailoring polymer structure to achieve mechanical properties and biodegradability to suit a variety of applications.
\end{abstract}

Key Words: Biodegradable polymers, tissue engineering, degradation, injectable polymers

Address for correspondence:

Pathiraja A. Gunatillake

CSIRO Molecular Science, Bag 10,

Clayton South MDC,

Vic 3169,

Australia

Telephone number: 61395452501

E-mail: Thilak.Gunatillake@csiro.au

\section{Introduction}

Biodegradable synthetic polymers offer a number of advantages over other materials for developing scaffolds in tissue engineering. The key advantages include the ability to tailor mechanical properties and degradation kinetics to suit various applications. Synthetic polymers are also attractive because they can be fabricated into various shapes with desired pore morphologic features conducive to tissue in-growth. Furthermore, polymers can be designed with chemical functional groups that can induce tissue in-growth.

Biodegradable synthetic polymers such as poly(glycolic acid), poly(lactic acid) and their copolymers, poly(p-dioxanone), and copolymers of trimethylene carbonate and glycolide have been used in a number of clinical applications (Shalaby, 1988; Holland and Tighe, 1992; Hayashi , 1994; Kohn and Langer, 1997; Ashammakhi and Rokkanen, 1997). The major applications include resorbable sutures, drug delivery systems and orthopaedic fixation devices such as pins, rods and screws (Behravesh et al., 1999; Middleton and Tipton, 2000). Among the families of synthetic polymers, the polyesters have been attractive for these applications because of their ease of degradation by hydrolysis of ester linkage, degradation products being resorbed through the metabolic pathways in some cases and the potential to tailor the structure to alter degradation rates. Polyesters have also been considered for development of tissue engineering applications (Hubbell, 1995; Thomson et al 1995a, Yazemski et al. 1996; Wong and Mooney, 1997), particularly for bone tissue engineering (Kohn and Langer, 1997; Burg et al., 2000).

Attempts to find tissue-engineered solutions to cure orthopaedic injuries/diseases have made necessary the development of new polymers that meet a number of demanding requirements. These requirements range from the ability of scaffold to provide mechanical support during tissue growth and gradually degrade to biocompatible products to more demanding requirements such as the ability to incorporate cells, growth factors etc and provide osteoconductive and osteoinductive environments. Furthermore, the development of in-situ polymerizable compositions that can function as cell delivery systems in the form of an injectable liquid/paste are becoming increasingly attractive in tissue engineering applications. Many of the currently available degradable polymers do not fulfil all of these requirements and significant chemical changes to their structure may be required if they are to be formulated for such applications.

Scaffolds made from synthetic and natural polymers, 
and ceramics have been investigated extensively for orthopaedic repair. This approach has advantages such as the ability to generate desired pore structures, matching size, shape and mechanical properties to suit a variety of applications. However, shaping these scaffolds to fit cavities/defects with complicated geometries, bonding to the bone tissues, and incorporating cells and growth factors, and requirement of open surgery are a few major disadvantages of this approach.

A material that can be used as a scaffold in tissue engineering must satisfy a number of requirements. These include biocompatibility, biodegradation to non toxic products within the time frame required for the application, processability to complicated shapes with appropriate porosity, ability to support cell growth and proliferation, and appropriate mechanical properties, as well as maintaining mechanical strength during most part of the tissue regeneration process. Development of a degradable polymer composition that can be injected arthroscopically has number of advantages in tissue engineering as against prefabricated scaffolds. A major advantage would be the possibility of administering the gel arthroscopically avoiding surgery in many cases. It also has the advantage of filling cavities with complex geometries, and to provide good bonding to tissue. Cells, growth factors and other components to support cell growth could also be incorporated with the gel. Such polymer systems also have the potential to be formulated to generate porous structure upon curing to facilitate nutrient flow to cells during growth and proliferation. Further, such polymers may be useful in pre-fabricating scaffolds with complex shapes with appropriate pore structures with biological components incorporated. However, in addition to the main requirements mentioned above, an injectable polymer composition must meet the following requirements to be useful in tissue engineering applications. Ideally the prepolymer should be in liquid/paste from, sterilizable without causing any chemical change, and have the capacity to incorporate biological matrix components. Upon injection the prepolymer mixture should bond to biological surface and cures to a solid and porous structure with appropriate mechanical properties to suit the application. The curing should be with minimal heat generation and the chemical reactions involved in curing should not damage the cells or adjacent tissues. The cured polymer while facilitating cell in-growth, proliferation and migration, should ideally be degraded to biocompatible components that are absorbed or released from the body.

The aim of this paper was to briefly review the major classes of biodegradable polymers and their potential in developing injectable polymer systems in tissue engineering. The review was focused on synthesis, potential applications, biocompatibility and biodegradation of these polymers to help the reader to further explore the use of these polymers or precursors with similar chemistries in developing injectable polymer compositions.

\section{Major classes of degradable polymers}

\section{Polyesters}

A vast majority of biodegradable polymers studied belong to the polyester family. Table 1 lists the key polymers in this family. Among these poly( $\alpha$-hydroxy acids) such as poly(glycolic acid) (PGA), poly(lactic acid) (PLA), and a range of their copolymers have historically comprised the bulk of published material on biodegradable polyesters and have a long history of use as synthetic biodegradable materials (Shalaby, 1988; Holland and Tighe, 1992; Hayashi , 1994: Kohn and Langer, 1997; Ashammakhi and Rokkanen, 1997) in a number of clinical applications. These polymers have been used as sutures (Cutright et al., 1971) plates and fixtures for fracture fixation devices (Mayer and Hollinger, 1995) and scaffolds for cell transplantation (Thomson et al. 1995b).

\section{Poly(glycolic acid), poly(lactic acid) and their copolymers}

Poly (glycolic acid) (PGA) is a rigid thermoplastic material with high crystallinity. (46-50\%). The glass transition and melting temperatures of PGA are 36 and $225^{\circ} \mathrm{C}$, respectively. Because of high crystallinity, PGA is not soluble in most organic solvents; the exceptions are highly fluorinated organic solvents such as hexafluoro isopropanol.

Although common processing techniques such as extrusion, injection and compression moulding can be used to fabricate PGA into various forms, its high sensitivity to hydrolytic degradation requires careful control of processing conditions (Mikos and Temenoff, 2000, Jen et al. 1999). Porous scaffolds and foams can also be fabricated from PGA, but the properties and degradation characteristics are affected by the type of processing technique. Solvent casting, particular leaching method and compression moulding are also used to fabricate PGA based implants.

The preferred method for preparing high molecular weight PGA is ring-opening polymerization of glycolide (Figure 1), the cyclic dimer of glycolic acid (Hollinger et al. 1997, Sawhney and Drumheller, 1998), and both solution and melt polymerization methods can be used. The common catalysts used include organo tin, antimony, or zinc. If stannous octoate is used, temperature of approximately $175^{\circ} \mathrm{C}$ is required for a period of 2 to 6 hours for polymerization. Although it is possible to synthesize these polymers by acid-catalysed polycondensation of respective acids, the resulting polymers generally have a low molecular weight and often poor mechanical properties (Agrawal et al. 1997).

The attractiveness of PGA as a biodegradable polymer in medical application is that its degradation product glycolic acid is a natural metabolite. A major application of PGA is in resorbable sutures (Dexon, American Cyanamide Co). Numerous studies (Chu, 1981a,b,c) have established a simple degradation mechanism via homogeneous erosion. The degradation process occurs in two stages, the first involves the diffusion of water into the amorphous regions of the matrix and simple hydrolytic 
Table 1. Biodegradable Polyesters

Polymer

Poly(glycolic acid)

Poly(lactic acid)<smiles>CC(C)C(=O)C1(C)CO1</smiles>

Poly(glycolic-co-lactic acid)<smiles>COCC(=O)OC(=O)C(C)C</smiles>

Poly(dioxanone)

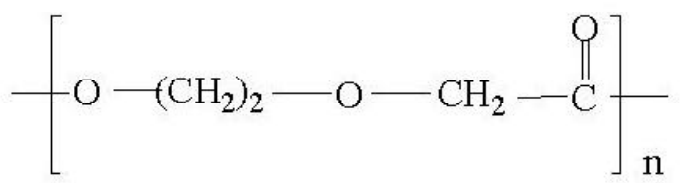

Poly(caprolactone)

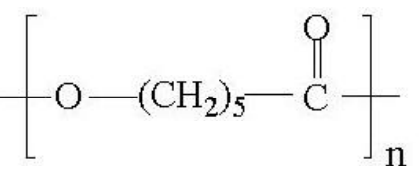

Poly(3-hydroxybutyrate)<smiles>CCCC(C)CC(C)OC</smiles>

Poly(3-hydroxyvalerate)

Poly(valerolactone)

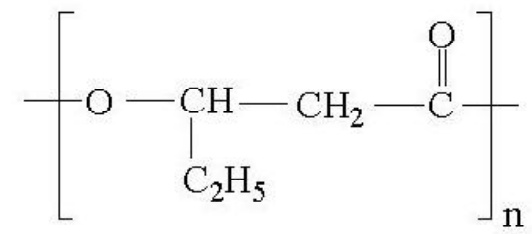

Poly(tartronic acid)
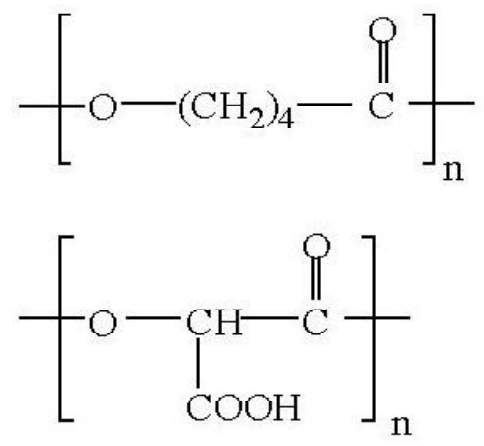

Poly $(\beta$-malonic acid) $)$

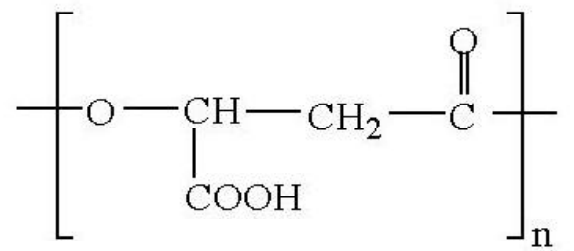




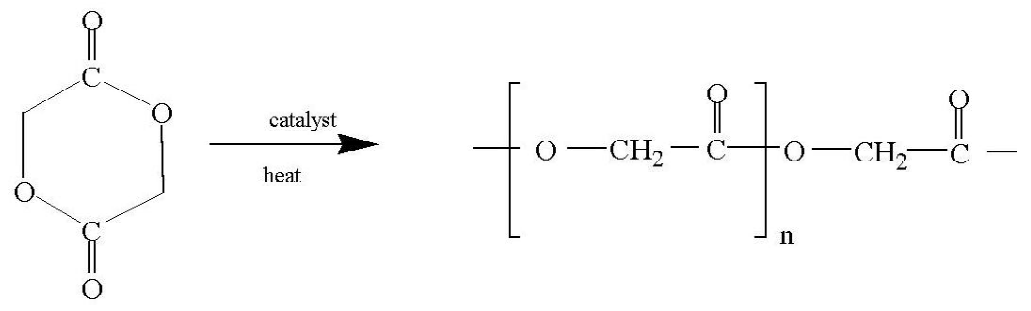

Figure 1.

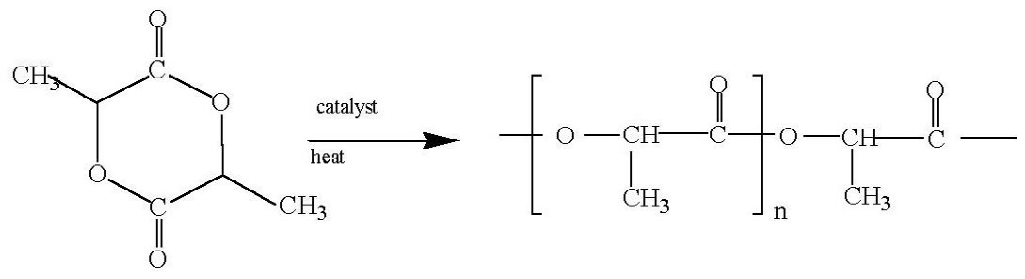

chain scission of the ester groups. The second stage of degradation involves largely the crystalline areas of the polymer, which becomes predominant when the majority of the amorphous regions have been eroded.

In a study of Dexon sutures in vitro, the first stage degradation predominates during the first 21 days and a further 28 days for the degradation of the crystalline regions. After 49 days, the reported weight loss was around $42 \%$ with complete loss of mechanical properties. Because of the bulk degradation of PGA, there is a sudden loss of mechanical properties. Although the degradation product glycolic acid is resorbable at high concentrations, they can cause an increase of localized acid concentration resulting in tissue damage. The ultimate fate of glycolic acid in-vivo is considered to be the conversion to carbon dioxide and water, with removal from the body via the respiratory system (Gilding, 1981). However, Hollinger (Hollinger, 1983) has suggested that only lactic acid follows this pathway, and that glycolic acid is converted into glyoxylate (by glycolate oxidase), which is then transferred into glycine after reacting with glycine transaminase.

Poly(lactic acid) is present in three isomeric forms $\mathrm{d}(-$ ), $1(+)$ and racimic $(d, 1)$ and the polymers are usually abbreviated to indicate the chirality. Poly(1)LA and poly(d)LA are semi-crystalline solids, with similar rates of hydrolytic degradation as PGA. PLA is more hydrophobic than PGA, and is more resistant to hydrolytic attack than PGA. For most applications the (1) isomer of lactic acid (LA) is chosen because it is preferentially metabolized in the body. PLILA, poly(lactic-glycolic acid) (PLGA) copolymers and PGA are among the few biodegradable polymers with Food and Drug Administration (FDA) approval for human clinical use.

The full range of copolymers of lactic acid and glycolic acid has been investigated. The two main series are those of (l)LA/GA and (dl)LA/GA. Gilding and Reed (1979). have shown that compositions in the 25 to $75 \%$ range for (1)LA/GA and 0 to $70 \%$ for the (dl) LA/GA are amorphous. For the (1)LA/GA copolymers, resistance to hydrolysis is more pronounced at either end of the copolymers compositions range (Miller et al., 1977; Gilding and Reed, 1979; Reed and Gilding, 1981; Vert et al.,
1984). The 70/30 GA/LA has the highest water uptake, hence the most readily degradable in the series. In another study (Miller et al., 1977) have shown that the 50/ 50 copolymer was the most unstable with respect to hydrolysis. However, it is generally accepted that intermediate copolymers are very much more unstable than the homopolymers. The first commercial use of this copolymer range was the suture material Vicryl (Ethicon Inc, Sommerville, NJ, USA; www.ethicon.com), which is composed of $8 \%$ (1)LA and $92 \%$ GA. The main application of (d,l- LA/GA) copolymer has been in the field of controlled drug release.

Biodegradation and biocompatibility of polylactides. The degradation of PLA, PGA and PLA/ PGA copolymers generally involves random hydrolysis of their ester bonds. PLA degrades to form lactic acid which is normally present in the body. This acid then enters tricarboxylic acid cycle and is excreted as water and carbondioxide. No significant amounts of accumulation of degradation products of PLA have been reported in any of the vital organs (Vert et al., 1984). Carbon ${ }^{13}$ labeled PLA has demonstrated little radioactivity in feces or urine indicating that most of the degradation products are released through respiration. It is also reported that in addition to hydrolysis PGA is also broken down by certain enzymes, especially those with esterase activity (William and Mort, 1977). Glycolic acid also can be excreted by urine.

The rate of degradation, however is determined by factors such as configurational structure, copolymer ratio, crystallinity, molecular weight, morphology, stresses, amount of residual monomer, porosity and site of implantation.

Both in-vitro and in-vivo studies have been carried out to ascertain the biocompatibility of PLA and PGA. Many studies suggests that these polymers are sufficiently biocompatible (Nelson et al. 1977, Hollinger, 1983) although certain studies (Schakenraad et al., 1989; VanSliedregt et al., 1990, 1992; Verheyen et al., 1993) suggest otherwise. Recent studies have shown that porous PLA-PGA scaffolds may be the cause of significant systemic or local reactions, or may promote adverse re- 
sponses during the tissue repair process. PLA-PGA copolymers used in bone repair applications have shown to be biocompatible, non-toxic and non-inflammatory (Nelson et al., 1977; Hollinger, 1983). Since PLA-PGA have been used successfully in clinical use as sutures, their use in fixation devices or replacement implants in musculoskeletal tissues may be considered safe.

Concerns about the biocompatibility of these materials have been raised when PLA and PGA produced toxic solutions probably as a result of acidic degradation (Tayler et al., 1994). This is a major concern in orthopaedic applications where implants with considerable size would be required, which may result in release of degradation products with high local acid concentrations. Another concern is the release of small particles during degradation, which can trigger an inflammatory response. It has been shown that as the material degrades the small particles that break off are phagocytized by macrophages and multinucleated giant cells (Gibbons, 1992). It was also noted that no adverse biological responses occur especially if the material volume is relatively small. In clinical studies where PGA was used as fracture fixation, foreign-body responses or osteolytic reactions have been reported (Böstman, 1991, 1992; Böstman et al., 1992a,b).

\section{Polylactones}

Poly(caprolactone) (PCL) is the most widely studied in this family (Holland and Tighe 1992; Hayashi, 1994). PCL is a semicrystalline polymer with a glass transition temperature of about $-60^{\circ} \mathrm{C}$. The polymer has a low melting temperature $\left(59\right.$ to $\left.64^{\circ} \mathrm{C}\right)$ and is compatible with a range of other polymers. PCL degrades at a much lower rate that PLA and is a useful base polymer for developing longterm, implantable drug delivery systems.

Pol(caprolactone) is prepared by the ring-opening polymerization of the cyclic monomer $\varepsilon$-caprolactone. Catalysts such as stannous octoate are used to catalyse the polymerization and low molecular weights alcohols can be used as initiator which also can be used to control the molecular weight of the polymer (In't Veld et al., 1997; Storey and Taylor, 1998).

Biodegradation and biocompatibility of polylactones. The homopolymer has a degradation time of the order of two to three years (Kronenthal, 1975; Holland and Tighe 1992; Middleton and Tipton, 2000). PCL with an initial average molecular weight of 50,000 takes about three years for complete degradation in-vitro (Gabelnick, 1983). The rate of hydrolysis can be altered by copolymerisation with other lactones, for example a copolymer of caprolactone and valerolactone degrades more readily (Pitt et al., 1981). Copolymers of $\varepsilon$ caprolactone with dl-lactide have been synthesized to yield materials with more rapid degradation rates (e.g., a commercial suture MONOCRYL, Ethicon) (Middleton and Tipton, 2000). PCL is considered a non-toxic and a tissue compatible material (Kronenthal, 1975).

Blends with other polymers and block copolymers and low molecular weight polyols and macromers based on caprolactone backbone are a few of the possible strategies

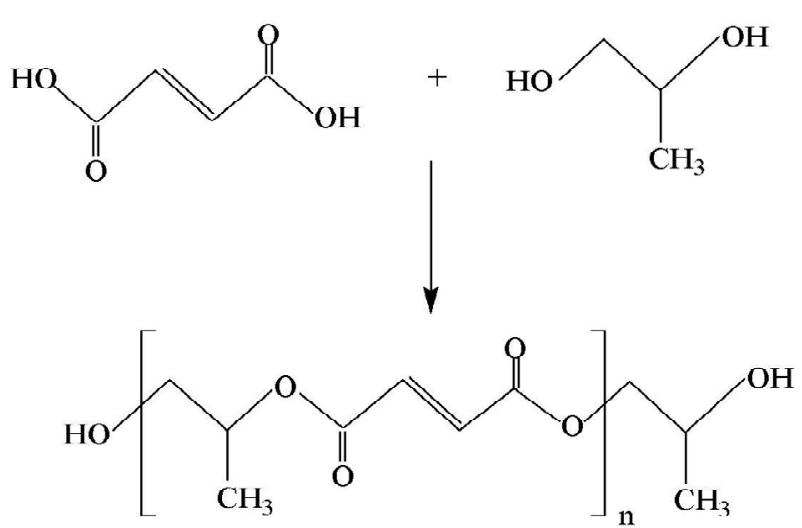

Poly(propylenefumarate) diol

Figure 2.

to explore this class of polymers for various applications.

\section{Poly(propylene fumarates)}

Recently, polyesters based on fumaric acid have received attention in the development of degradable polymers, and the most widely investigated is the copolyester poly(propylene fumarate) (PPF) (Figure 2). The degradation of this copolymer leads to fumaric acid, a naturally occurring substance, found in the tri-carboxylic acid cycle (Krebs cycle), and 1,2-propanediol, which is a commonly used diluent in drug formulations. The copolymer also has unsaturated sites in its backbone, which could be used in subsequent cross-linking reactions.

PPF based degradable polymer compositions including injectable biodegradable materials have been reported in the literature (Kharas et al., 1997; Peter et al., 1998a,b; Temenoff and Mikos, 2000). Injectable systems developed based on PPF have the advantage of employing chemical cross-linking overcoming some of the disadvantages in photo cross-linkable systems. Photo-cross-linkable systems have limited applications for treatment of deep crevices in bone. A number of studies have reported on the synthesis, properties (Kharas et al., 1997; Peter et al., 1998a; Temenoff and Mikos, 2000) and in-vivo degradation (Yaszemski et al., 1994; Frazier et al., 1997; Peter et al., 1998a) characteristics of poly(propylene fumarate). The copolymers degrade to propylene glycol, poly(acrylic acidco-fumaric acid) and fumaric acid (Temenoff and Mikos, 2000). Cross-linking usually occurs with methylmethacrylate or $\mathrm{N}$-vinyl pyrolidone and benzoyl peroxide as the initiator.

A number of methods have been reported to prepare $\mathrm{PPF}$, and each results in different polymer properties (Peter et al., 1997a,b, 1999; Temenoff and Mikos 2000). Products with complex structure are obtained due to side reactions involving different modes of addition. In one method diethyl fumarate and propylene glycol with para-toluene sulfonic acid catalyst are reacted at $250^{\circ} \mathrm{C}$ (Sanderson, 1988). The yield in this process is only $35 \%$. In another method, propylene glycol and fumaric acid are heated initially at $145^{\circ} \mathrm{C}$ and gradually increasing the temperature to $180^{\circ} \mathrm{C}$. Poly(propylene fumarate) diol with mo- 


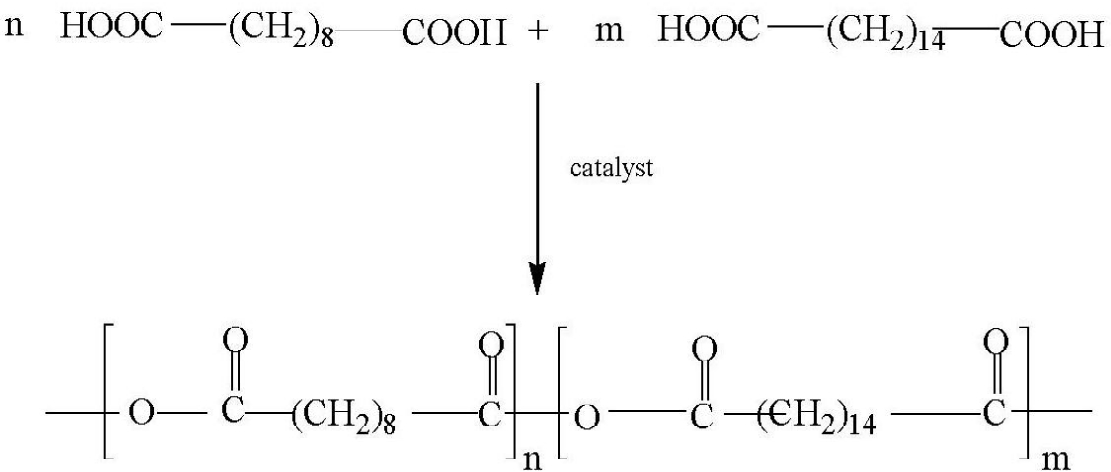

Figure 3.

lecular weights in the range 500 to 1200 and polydispersity 3 to 4 can be typically prepared by this method (Gerhart and Hayes, 1989). A third method involves preparing the bis-(hydroxylpropyl) fumarate trimer and propylene bis(hydrogen maleate) trimer by reacting propylene glycol/fumaric acid, and maleic anhydride/propylene glycol, respectively (Domb, 1989). The two trimers are then reacted at $180^{\circ} \mathrm{C}$ to produce PPF. The bis-(hydroxypropyl) fumarate trimer can also be prepared at ambient temperature by reacting fumaryl chloride and propylene glycol (Peter et al., 1997a). The purified trimer is reacted at $160^{\circ} \mathrm{C}$ in the presence of transesterification catalyst antimony trioxide to produce PPF. PPF with molecular weights in the range 750 to 1500 could be prepared by this method. The polydispersity ranged from 1.7 to 3 .

It appears that achieving high molecular weight PPF is difficult because of side reactions, particularly due to the presence of the backbone double bond. Accordingly, incorporation of fillers, or further reactions to form crosslinked net works would be required to achieve good mechanical strength. The mechanical properties vary greatly depending on the method of synthesis and the cross-linking agent used. Mechanical properties could be improved by incorporating ceramic materials such as tricalcium phosphate (TCP), calcium carbonate or calcium sulfate. These composite materials exhibit compressive strengths in the range 2 to $30 \mathrm{MPa}$. $\beta$-TCP was particularly useful for reinforcement, and compositions without TCP reinforcement disintegrated very early in the implant(Temenoff and Mikos, 2000).

Cross-linking characteristics reported for PPF, N-vinyl pyrrolidone (N-VP), benzoyl peroxide, sodium chloride, and TCP indicate that for a range of formulations, the maximum temperature varied within 38 to about $48^{\circ} \mathrm{C}$, compared to $94^{\circ} \mathrm{C}$ observed for polymethylmethacrylate (PMMA) cements. The curing times varied between 1 and $121 \mathrm{~min}$, which allows the composites to be tailored to specific applications. The compressive strengths varied between 1 and $12 \mathrm{MPa}$ (Peter et al., 1998a).

Biocompatibility and biodegradation of PPF. PPF un- dergoes bulk degradation and degradation time is dependent on polymer structure as well as other components. PPF degrades by hydrolysis to fumaric acid and propylene glycol. Based on in-vitro studies, the time required to reach $20 \%$ loss in original weight ranged from 84 (PPF/ $/$-TCP composite) to over 200 days ( $\mathrm{PPF} / \mathrm{CaSO}_{4}$ composite) (Peter et al., 1997b; Kharas et al., 1997). ß-TCP in these compositions not only increased mechanical strength, but also acts as a buffer making the $\mathrm{pH}$ change minimal during the degradation process.

PPF does not exhibit a deleterious long-term inflammatory response when implanted subcutaneously in rats. A mild inflammatory response was observed initially and a fibrous capsule formed around the implant at 12 weeks (Peter et al., 1998a).

\section{Polyanhydrides}

Polyanhydrides are one of the most extensively studied (Holland and Tighe, 1992; Kohn and Langer, 1997; Ashammakhi and Krokkanen, 1997) classes of biodegradable polymers with demonstrated biocompatibility and excellent controlled release characteristics. Polyanhydrides degrades by surface erosion (Kohn and Langer, 1997) and their main applications are in controlled drug delivery. Polyanhydride based drug delivery systems have been utilized clinically (Brem et al., 1995).

Polyanhydrides are synthesized (Figure 3 ) by dehydration of the diacid or a mixture of diacids by melt polycondensation (Domb and Langer, 1987). The dicarboxylic acid monomers are converted to the mixed anhydride of acetic acid by reflux in excess acetic anhydride. High molecular weight polymers are prepared by melt-polycondensation of prepolymer in vacuum under nitrogen sweep.

Langer and coworkers (Brem, et al., 1995; Burkoth and Anseth, 2000) have synthesized polyanhydrides (I) for drug delivery applications. Polyanhydride (I) is used to deliver carmustine, an anticancer drug, to sites in the brain where a tumor has been removed. The degradation products of (I) are non-toxic and have controlled surface

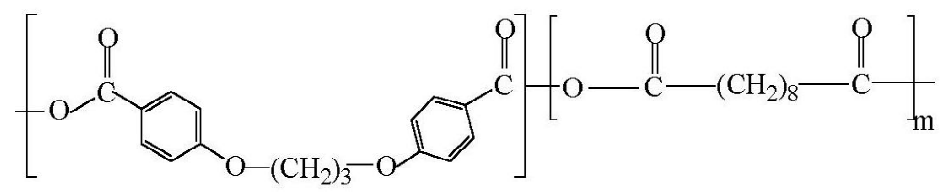



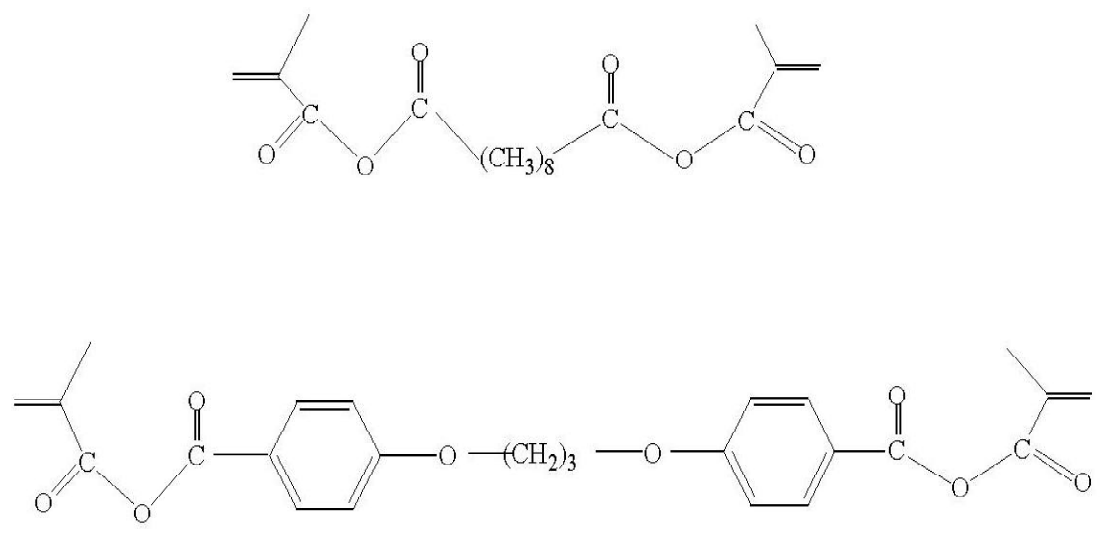

Figure 4.

erosion degradation mechanism that allows delivery of drugs at a known rate.

Polyanhydrides have limited mechanical properties that restrict their use in load-bearing applications such as in orthopaedics. For example poly[1,6-bis(carboxyphenoxy) hexane] has a Young's modulus of $1.3 \mathrm{MPa}$ (Leong et al., 1985; Uhrich et al., 1997) which is well below the modulus of human bone ( 40 to $60 \mathrm{MPa}$ ). To combine good mechanical properties of polyimides with surface-eroding characteristics of polanhydrides, poly(anhydrides-co-imides) have been developed (Attawia et al., 1995; Uhrich et al., 1995), particularly for orthopaedic applications. Examples include poly-[trimellitylimidoglycine-co-bis(carboxyphenoxy) hexane], and poly[pyromellitylimidoalanine-co1,6-bis(carboph-enoxy)-hexane] (Attawia et al., 1995; Seidel et al., 1996). These poly(anhydride-co-imides) have significantly improved mechanical properties, particularly compressive strengths. Materials with compressive strengths in the 50 to $60 \mathrm{MPa}$ range have been reported for poly(anhydrides-co-imides) based on succinic acid trimellitylimidoglycine and trimellitylimidoalanine (Uhrich et al., 1995). The degradation of these copolymers occurred via hydrolysis of anhydride bonds, followed by the hydrolysis of imide bonds.

Photo cross-linkable polyanhydrides have also been developed for use in orthopaedic applications, particularly focusing on achieving high mechanical strength. The systems developed are based on dimethacrylated anhydrides (Muggli et al., 1998; Burkoth and Anseth, 2000). Figure 4 shows dimethacrylate macrommers based on sebacic acid and 1,6-bis(p-carboxyphenoxy)hexane. Both ultraviolet (UV) and visible light cure methods have been investigated with these macromonomers. The most effective means of photopolymerization of these macromonomers was found to be $1.0 \mathrm{wt} \%$ camphorquinone and $1.0 \mathrm{wt} \%$ ethyl-4-N,N-dimethyl aminobenzoate with $150 \mathrm{~mW} / \mathrm{cm}^{2}$. Combination of redox type and visible initiation has provided means of achieving efficient curing of thick samples.

Depending on the monomers used, the mechanical properties as well as degradation time can be varied. Compressive strengths of $30-40 \mathrm{MPa}$, and tensile strengths of 15-27 MPa, similar to those of cancelleous bone, have been reported (Anseth et al., 1997).
Biocompatibility and biodegradation of polyanhydrides. Polyanhydrides are biocompatible (Laurencin et al., 1990), have well-defined degradation characteristics, and have been used clinically in drug delivery systems (Leong et $a l ., 1985)$. Polyanhydrides degrade by hydrolysis of the anhydride linkage. The hydrolytic degradation rates can be altered by simple changes in the polymer backbone structure by choosing the appropriate diacid monomers. Poly(sebasic acid) degrades quickly (about 54 days in saline), while poly(1,6-bis(- $p$-carboxyphenoxy)hexane degrade much more slowly (estimated 1 year). Accordingly, combinations of different amounts of these monomers would result in polymer with degradation properties custom-designed for a specific application (Temenoff and Mikos, 2000).

Minimal inflammatory responses to sebacic acid/1,3bis(p-carboxyphenoxy) propane (SA/CPP) systems have been reported when implanted subcutaneously in rats up to 28 weeks. Loose vascularized tissue had grown into the implant at 28 weeks, with no evidence of fibrous capsule formation (Laurencin et al., 1990). No data have been reported about polymer sterilizability and heat generation during polymerization. A 12 week study using 2-3 $\mathrm{mm}$ diameter full thickness defect in the distal femur of rabbits showed good tolerance of the SA/CPP polymer system and osseous tissue in the outer zone of some implants (Laurencin et al., 1990).

\section{Tyrosine-derived polycarbonates}

Tyrosine-based polycarbonates (Figure 5) have been reported as promising degradable polymers for use in orthopaedic applications (Muggli et al., 1998; Tangpasuthadol et al., 2000a,b). These polymers possess three potentially hydrolysable bonds: amide, carbonate and ester. Studies have shown (Muggli et al., 1998) that the carbonate group hydrolyzes at a faster rate than the ester group, and the amide bond is not labile in vitro. Since the hydrolysis of the carbonate groups yields two alcohols and carbon dioxide, the problem of acid bursting seen in polyesters is alleviated. By variation of the structure of the pendant $\mathrm{R}$ group, polymers with different mechanical properties, degradation rates as well as cellular response could be prepared. Polycarbonate having an ethyl ester pendant group has shown to be strongly osteoconductive 


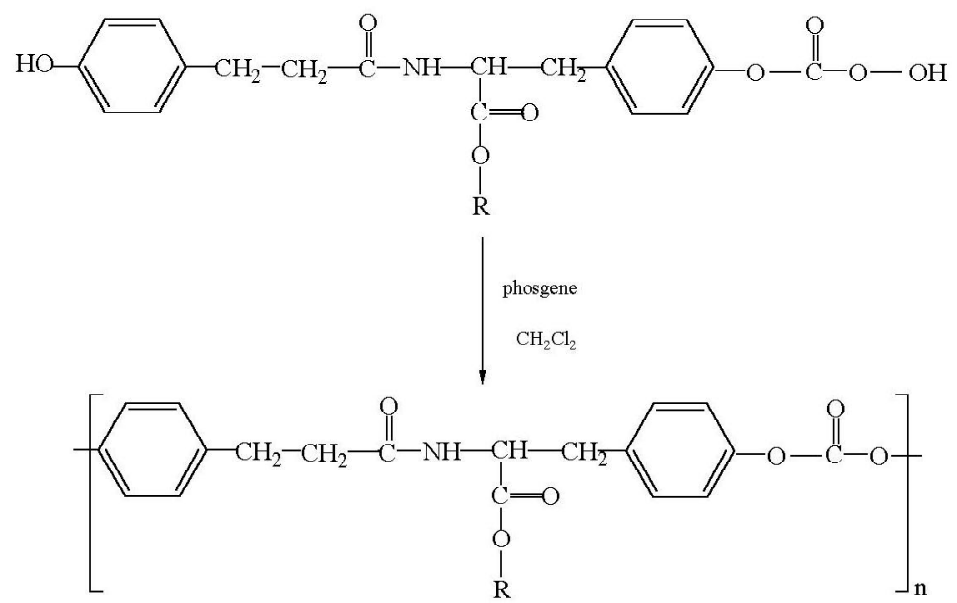

Figure 5.

and good bone apposition, and possesses sufficient mechanical properties for load bearing bone fixations. Invivo studies have demonstrated that the polymer was biocompatible and promoted significant bone growth (Pulapura and Kohn, 1992; Muggli et al., 1998).

\section{Polyorthoesters}

Poly(orthoester)s (POE) are another family of polymers identified as degradable polymers suitable for orthopaedic applications. Heller and coworkers reported on the synthesis of a family of polyorthoesters (Figure 6) that degrades by surface erosion ( $\mathrm{Ng}$ et al., 1997). With the addition of lactide segments as part of the polymer structure, tunable degradation times ranging from 15 to hundreds of days can be achieved. The degradation of the lactide segments produces carboxylic acids, which catalyze the degradation of the orthoester ( $\mathrm{Ng}$ et al., 1997).

Preliminary in-vivo studies have shown that POE (Figure 6) to increase bone growth in comparison with poly(dilactide-co-glycolide) (Andriano et al., 1999).

\section{Polyurethanes}

Polyurethanes (PU) represent a major class of synthetic elastomers that have been evaluated for a variety of medical implants, particularly for long-term implants (Pinchuk, 1994; Lamba et al., 1998). They have excellent mechanical properties and good biocompatibility. They are used in the fabrication of medical implants such as cardiac pace makers and vascular grafts. Recent developments in siloxane-based polyurethanes, which have greater in-vivo stability than conventional polyetherurethanes (e.g., poly(tetramethylene oxide) (PTMO)-based) have provided opportunities for development of a range of medical implants for chronic applications (Gunatillake et al., 2001).

Polyurethanes can also be designed to have chemical linkages that are degradable in the biological environment (Zdrahala and Zdrahala, 1999). Since polyurethanes can be tailored to have a broad range of mechanical properties and good biocompatibility, there has been some interest to develop degradable polyurethanes for medical applications such as scaffolds for tissue engineering (Zdrahala and Zdrahala, 1999). However, a major problem has been the toxicity of degradation products, particularly those derived from the diisocyanate component. For example, degradation products of polyurethanes based on diisocyanates such as 4,4'-methylenediphenyl diisocyanae (MDI) and toluene diisocyanate (TDI) are toxic (McGill and Motto, 1974; Gogolewski and Pennings, 1982). Accordingly, in designing degradable polyurethanes diiscoyanates such as lysine diisocyanate (LDI) (2,6-diisocyanatohexanoate) and other aliphatic diisocyanates like hexamethylene diisocyanate (HDI) and 1,4-butanediisocyanate have been used.

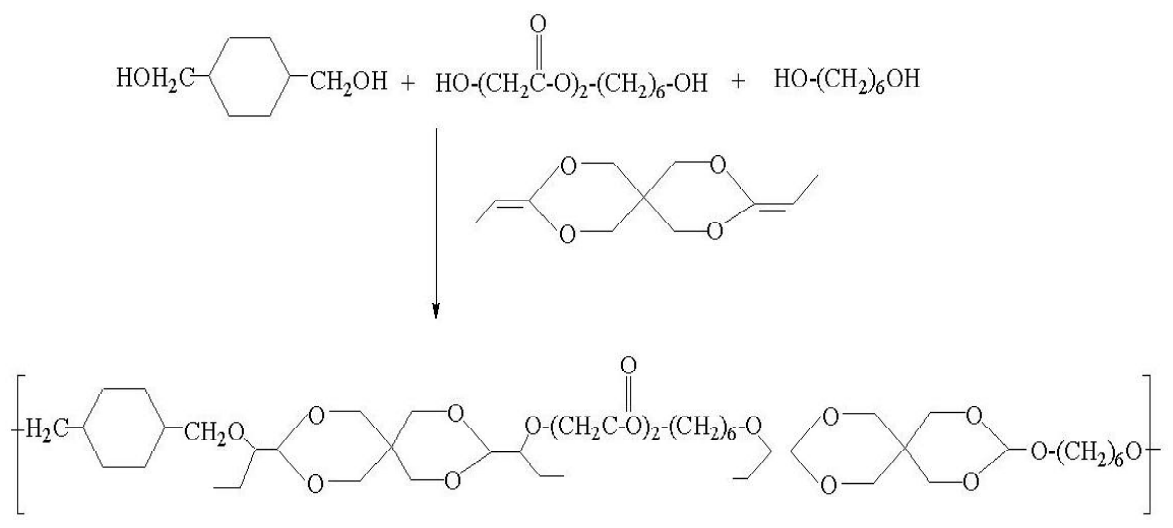

Figure 6. 


\section{Properties and bidegradation of aliphatic diisocyanate base polyurethanes:}

A number of studies have been reported on the synthesis and properties of a range of polyurethanes based on lysine diisocyanate (LDI) (II).<smiles>CCOC(=O)C(C=O)CCC=O</smiles>

lysine diisocyanate

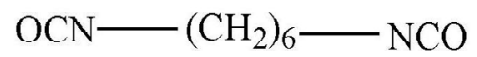

\section{1,6-hexane diisocynate}

Lysine diisocyanate is not commercially available (being developed by Kyowa Hakko Kogyo Co., Chiyoda-Ku, Tokyo, Japan) but can be prepared from L-lysine monohydrochloride (Bruin et al., 1988; Storey et al., 1993). Storey et al (1994) have prepared poly(ester urethane) networks from LDI and a series of polyester triols based on dl-lactide, $\gamma$-caprolactone, and their copolymers. Networks based on poly(dl-lactide) were rigid (glass transition temperature $\mathrm{Tg}=60^{\circ} \mathrm{C}$ ) with ultimate tensile strengths of $\sim 40$ to $70 \mathrm{MPa}$, whereas those based on caprolactone triols were low modulus elastomers with tensile strengths of 1 to $4 \mathrm{MPa}$. Networks based on copolymers were more elastomeric (elongation up to $600 \%$ ) with compressive strengths between 3 to $25 \mathrm{MPa}$. Hydrolytic degradation under simulated physiological conditions were dependent on the type of triol and dl-lactide based networks were the most resistant with no degradation observed for 60 days, caprolactone based triol networks were resistant up to 40 days whereas the high lactide based copolymer networks were the least resistant and substantial degradation observed in about 3 days.

Bruin et al. (1988) have reported on the synthesis of degradable polyurethane networks based on star-shaped polyester prepolymers. The star-prepolymers were prepared from myoinisitol, a pentahydroxy sugar molecule by ring-opening copolymerisation of 1-Lactide or glycolide with caprolactone. The prepolymers were cross- linked using 2,6-diisocyanatohexanoate. The degradation products of these PU networks are considered non-toxic. The resulting network polymers were elastomeric with elongation in the range 300 to $500 \%$ and tensile strengths varying between 8 to $40 \mathrm{MPa}$ depending on the branch length etc. Preliminary experiments in guinea pigs have shown that the polyurethanes biodegrade when implanted subcutaneously. Polyurethane networks based on LDI and poly(glycolide-co- $\gamma$-caprolactone) macrodiol was evaluated by Bruin et al. (1990) as two-layer artificial skin. The degradation of the skin in-vivo was faster than that in in-vitro. Subcutaneous implantation in guinea pigs showed that the porous polyurethane networks allowed rapid cell in-growth, degraded almost completely 4-8 weeks after implantation and evoked no adverse tissue reaction.

Zang et al. (2000) have developed a peptide based polyurethane scaffold for tissue engineering. LDI was reacted first with glycerol to form a prepolymer, which upon reaction with water produced a cross-linked porous sponge due to liberation of carbon dioxide. Initial cell growth studies with rabbit bone marrow stromal cells have shown that the polymer matrix supported cell growth and was phenotypically similar to those grown on tissue culture polystyrene.

Hirt et al. (1996) and De Groot et al. (1990) reported on the synthesis and properties of degradable polyurethanes based on LDI, 2,2,4-triethylhexamethylene diisocyanate and a number of polyester and copolyester polyols such as Diorez ${ }^{\circledR}$, caprolactone, ethylene glycol copolymers, and poly hydroxy butyrate and valerate copolymers. The polyurethanes ranged from elastomers with elongations at break as high as $780 \%$, but with low tensile strengths (5.8 to 8.1 MPa). Saad et al. (1997) reported on the cell and tissue interaction of four such polymers prepared from 2,2,4-trimethylhexamethylene diisocyanate and 2,6-diisocyanato methyl caproate, and polyols a, $\omega$-dihydroxy-poly $(R-3$-hydroxybutyrate-co- $(R)$ 3-hydroxyvalerate)-block-ethylene glycol], and two commercial diols, Diorez ${ }^{\circledR}$ and PCL-diol. In-vitro studies indicated that these polyesterurethanes did not activate macrophages and showed good level of cell adhesion, and growth, which were also confirmed by in-vivo results.

Structure-property relationships of degradable polyurethanes based on 2,6-diisocyanato methyl caproate, polycaprolactone, polyethylene oxide (PEO) and an amino acid chain extender (phenylalanine) have been investigated by Skarja and Woodhouse $(1998,2000)$. Their results showed that PEO based polyetherurethane (PEU) were generally weaker but PCL based materials were relatively strong. However, no results were reported on the degradation of these polyurethanes.

Gogolewsky and Pennings $(1982,1983)$ have reported on a design of an artificial skin composed of polylactide/ polyurethane mixtures where the PU was non-degradable. In-vivo studies with guinea pigs showed that the artificial skin adhered to wound well, and protected from fluid loss and infections up to 40 days exhibiting potential as a skin substitute.

Micro-porous polyurethane amide and polyurethaneurea scaffolds have been evaluated by Spaans et al. (2000) for repair and replacement of knee-joint meniscus. The soft segments in these polyurethanes were based on 50/ 50 l-lactide/PCL and chain extenders were adipic acid and water, the reaction of latter with 1,4-butane diisocyanate provided carbon dioxide to produce porous scaffolds. Salt crystals were also added to produce porous structure, and the addition of surfactants combined with ultrasonic waves regulated the pore structure. Porous scaffolds with porosity of 70 to $80 \%$ were achieved by this technique. These scaffolds exhibited tearing problems 
during suturing (De Groot et al.., 1996), which was partly circumvented by using a different suturing system. A meniscal replica implanted contained only fibro-cartilage after 18 weeks and decreased the degradation of the articular cartilage.

Biocompatibility and biodegradation of degradable polyurethanes. Although a number of studies discussed above indicate that the biocompatibility of degradable polyurethanes appear to be satisfactory based on both invitro and in-vivo studies. Animal studies showed rapid cell in-growth with no adverse tissue reactions. However, the effect of degradation products and how those products are removed from the body are not clearly understood.

\section{Polyphosphazenes}

The polyphosphazenes consist of several hundred different polymers with the general structure (VI) (Mark et al., 1992). Different polyphosphazenes are made by means of macromolecular substitution reactions carried out on a reactive polymeric intermediate, poly(dichlorophosphazene), $\left(\mathrm{NPCl}_{2}\right)$ n. Although most polyphosphazenes are biostable, incorporation of specific side groups such as amino acid esters, glucosyl, glyceyl, lactate, or imidazolyl units can render polyphosphazenes biodegradable (Alcock, 1999; Behravesh et al., 1999; Qui and Zhu, 2000).

(VI)

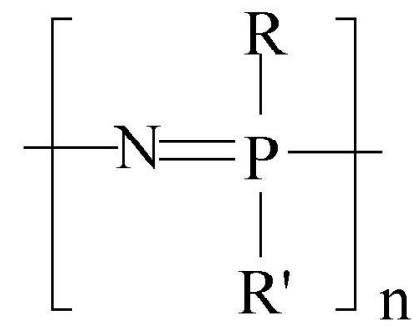

Hydrolysis of the polymer leads to free side group units, phosphate and ammonia due to backbone degradation.

Biocomaptibility and biodegradation. Laurencin et al. (1993) have investigated methylphenoxy and either imidazolyl or ethylglycinate substituted polyphosphazenes for skeletal tissue regeneration. Both materials supported the growth of MC3T3-E1, an osteogenic cell line. Increase in imidazolyl side groups resulted in a reduction in cell attachment and growth on the polymer surface and an increase in the rate of degradation of the polymer. In contrast, substitution with ethylglycinato group favoured increased cell adhesion and growth and also an increase in the rate of degradation of the polymers.

In another study (Laurencin et al., 1996), porous matrices of poly[(50\% ethylglycinato) $(50 \%$ pmethylphenoxy) phosphazene] with pore sizes of 150 to $250 \mu \mathrm{m}$ have been shown to be good substrate for osteoblast-like cell attachment and growth.

\section{Development of injectable and biodegradable polymers for tissue engineering}

The devlopment of injectable polymer compositions for tissue engineering applications requires the preparation of precursors with appropriate physical properties and functional groups for curing at a second stage. A choice of a suitable curing method with minimal heat generation and chemical reactions that do not interfere with biological components is also very important for developing such polymer compositions. A range of oligomeric precursors with degradable backbones has been reported in the literature (Leong et al., 1985, Attawia et al., 1995; Uhrich et al., 1995; Seidel et al., 1996; Kharas et al., 1997; Uhrich et al., 1997; Muggli et al., 1998; Peter et al., 1998b; Burkoth and Anseth, 2000; Temenoff and Mikos, 2000) with potential to develop such polymer compositions. Many of these are based on the various families of degradable polymers discussed previously. Majority of them contain ester functional groups in the backbone. Table 2 provides a summary of the properties of common biodegradable polymers while Table 3 provides some of the macrodiols and macromers with degradable backbones suitable for the development of injectable polymer compositions.

Only a few synthetic polymer-based injectable compositions have been reported in the literature. Poly(propylene fumarate) (Kharas et al., 1997; Peter et al., 1998b; Temenoff and Mikos, 2000) and dimethacrylated polyanhydrides (Leong et al., 1985; Attawia et al., 1995; Uhrich et al., 1995; Seidel et al., 1996; Uhrich et al., 1997, Muggli et al; 1998; Burkoth and Anseth, 2000) are two types of precursors that have been reported recently as in-situ polymerizable systems with potential for orthopaedic tissue engineering applications. Poly(ortho esters) based injectable polymer has also been reported (Heller et al., 2002) for use in pain control and periodontal treatment. The in-situ cross-linking of fumarates has been achieved by using benzoyl peroxide initiator in the presence of methylmethacrylate and $\mathrm{N}$ vinyl pyrolidone while UV and visible light initiators have been used for dimethacrylated polyanhydrides.

\section{Conclusions}

A vast majority of biodegradable polymers studied belong to polyester family and poly(glycolic acid), poly (lactic acid) and their copolymers have historically comprised the bulk of published material. These polymers have a relatively long history of use in a number of clinical applications. They will continue to play a key role in various forms for medical applications requiring biodegradable polymers. Polyesters offer synthetic chemists many opportunities to design polymers through combination of different monomers to achieve property requirements to suit a variety of applications. Additionally, the development of precursors such as polyols and macromonomers based on polyesters may find uses in injectable and insitu curable polymer formulations. Poly(propylene fumarate) is one example of a recently developed polyesterbased injectable polymer system.

Polyanhydride is another family of polymers studies extensively with demonstrated biocompatibility and excellent controlled release characteristics. Polyanhydride degrade by bulk erosion and their main applications are in controlled drug delivery. Recently photocross-linkable 
Table 2 Properties of biodegradable polymers

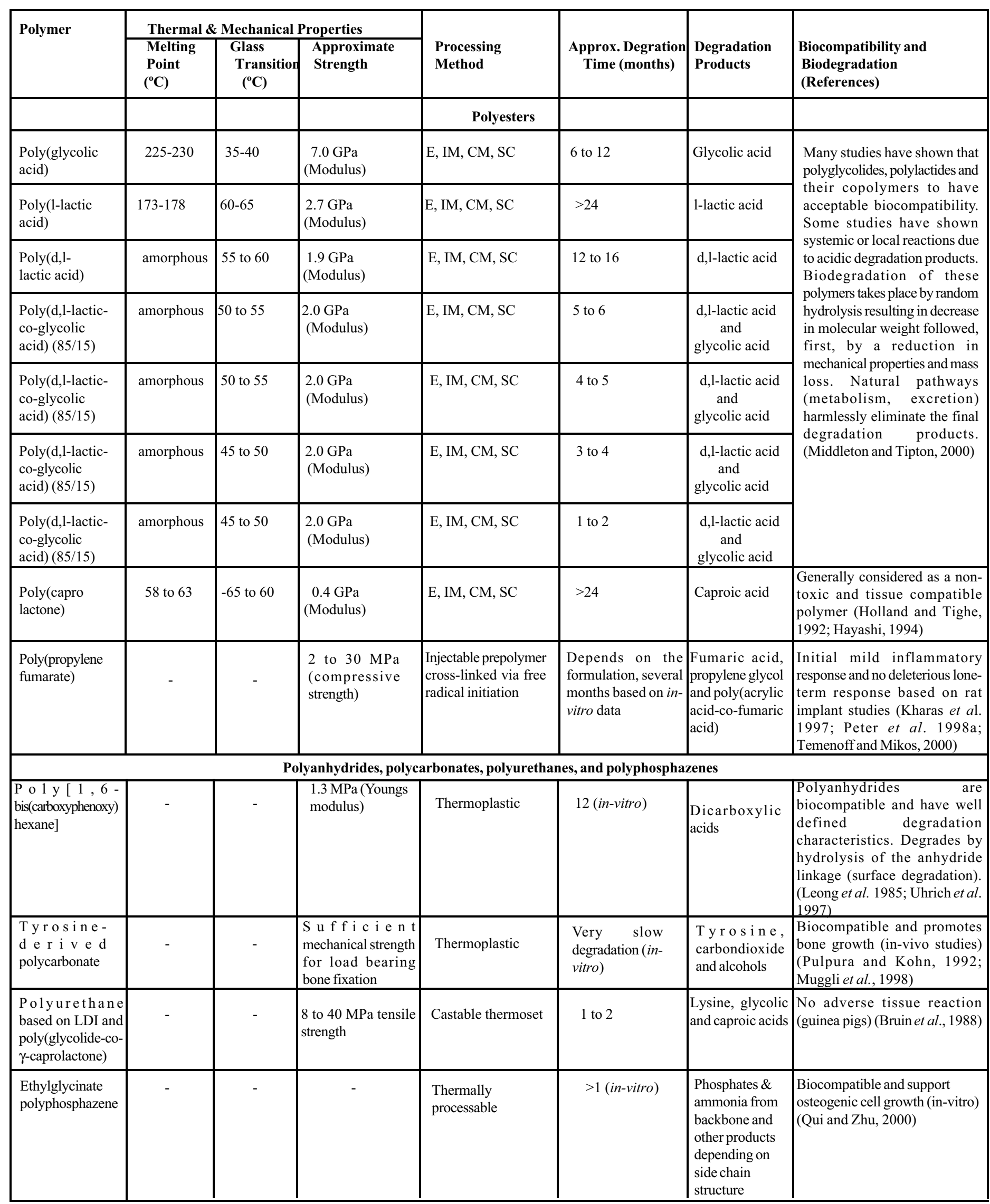

This summary was prepared based on the information taken from the literature reviewed in this article and the data should be used as a guide only $\mathrm{E}=$ extrusion, $\mathrm{IM}=$ injection moulding, $\mathrm{CM}=$ compression moulding, $\mathrm{SC}=$ solvent casting,

Sufficient data are not available to provide comprehensive list of properties for polymers in these families. 
Table 3. Precursors for developing injectable biodegradable polymers<smiles>CCCCCCCC(=O)OC(C)(CCCCCCC(C)(C)O)CCC(=O)OC(C)(C)O</smiles>

Poly(caprolactone) diol<smiles>CC(O)CC(C)OC(=O)/C=C/C(=O)OC(C)CC(C)(C)O</smiles>

Poly(propylenefumarate) diol<smiles>CC(C)(O)CCCCCC(=O)OCCCCC(=O)O</smiles>

Poly(tetramethyleneadipate) diol

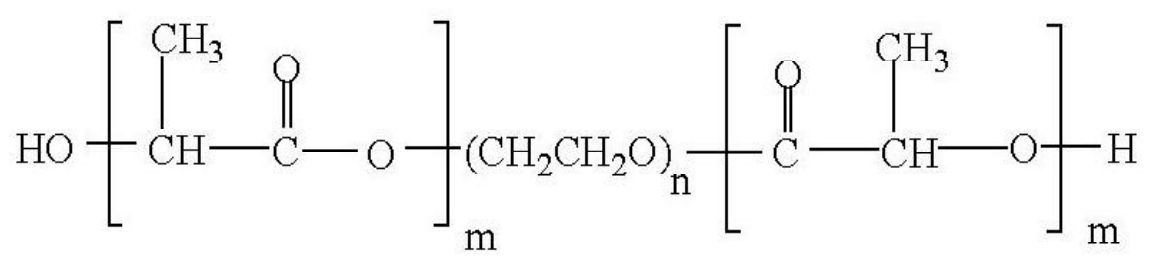

Poly(ethyleneglycol-co-lactic acid) diol<smiles>C=C(C)C(=O)COC(=O)C(=O)CC(C)(C)C(=O)COC(=O)C(=C)C</smiles>

Poly(sebacic acid) dimethacrylate<smiles>C=C(C)C(=O)OC(=O)c1ccc(OC(C)C(C)(C)Oc2ccc(C(=O)OC(=O)C(=O)OC(C)C)cc2)cc1</smiles>

Poly[1,3-bis( $p$-carboxyphenxy)propane] dimethacrylate 
polyanhydrides have been developed for use in orthopaedic applications. Tyrosine-derived polycarbonates, polyorthoseters, polyurethanes and polyphosphazenes have also been investigated to explore their potential as biodegradable polymers.

Review of the literature indicates that relatively few attempts have been made to develop injectable polymer compositions for use in tissue engineering applications. The key challenges in developing such compositions include the choice of appropriate precursors that would degrade to biocompatible and resorbable compounds, the ability to incorporate cells and other components to support cell attachment and proliferation, ability to cure insitu in the in-vivo environment with minimal heat generation, and the ability to control degradation kinetics to suit the intended application.

Polyurethanes offer many advantages in the design of injectable and biodegradable polymer compositions. As a class of polymers, polyurethanes generally have good biocompatibility. They also offer substantial opportunities to tailor polymer structure to achieve a broad range of mechanical properties. By choice of star, dendritic or hyperbranched prepolymers, one can introduce structural variations to tailor degradation kinetics as well as incorporation of appropriate functional groups for improved cell attachment. In the rapidly advancing field of tissue engineering, polyurethanes offer numerous opportunities to develop suitable scaffolds for a variety of applications.

\section{References}

Agrawal CM, Athanasiou KA, Heckman JD (1997) Biodegradable PLA/PGA polymers for tissue engineering in orthopaedica. Material Science Forum 250: 115128.

Alcock HR (1999) Inorganic-organic polymers as route to biodegradable materials. Macromol Symp 144: 33-46.

Andriano KP, Tabata Y, Ikada Y, Heller J (1999) In vitro and In vivo comparison of bulk and surface hydrolysis in absorbable polymer scaffolds for tissue engineering. J Biomed Mater Res (Appl Biomater) 48: 602-612.

Anseth KS, Svaldi DC, Laurencin CT, Langer R (1997) Photopolymerisation of novel degradable networks for orthopaedic applications. In: Photopolymerization. Scranton A, Bowman C, Peiffer R, eds. ACS Symposium Series 673; American Chemical Society, Washington DC. pp 189-202.

Ashammakhi N, Rokkanen P (1997) Absorbable polyglycolide devices in trauma and bone surgery. Biomaterials 18: 3-9.

Attawia MA, Uhrich KE, Botchwey E, Fan M, Langer R, Laurencin CT (1995) Cytotoxocity testing of poly(anhydride) for orthopaedic applications. J Biomed Mater Res 29: 1233-1240.

Behravesh E, Yasko AW, Engle PS, Mikos AG (1999) Synthetic biodegradable polymers for orthopaedic applications. Clin Orthop 367S: 118-185.

Böstman OM (1991). Osteolytic changes accompanying degradation of absorbable fracture fixation implants. J Bone Joint Surg 73B: 679-682.
Böstman OM (1992) Intense granulomatous inflammatory lesions associated with absorbale internal fixation devices made of polyglycolide in ankle fractures. Clin Orthop 278: 178-199.

Böstman O, Päivaärinta U, Partio E, Vasenius J, Manniner M, Rokkanen P (1992a) Degradation and tissue replacement of an absorbable polyglycolide screw in the fixation of rabbit osteomies. J Bone Joint Surg 74A: 1021-1031.

Böstman O, Partio E, Hirvensalo E, Rokannen P (1992b) Foreign-body reactions to polyglycolide screws. Acta Orthop Scand 63: 173-176.

Brem H, Piantadosi S, Burger PC, Walker M, Selker R, Vick NA, Black K, Sisti M, Brem G, Mohr G, Muller P, Morawetz R, Schold SC (1995) Lancet 345: 1008.

Bruin P, Venstra GJ, Nijenhuis AJ, Pennings AJ (1988) Design and synthesis of biodegradable poly(esterurethane) elastomer networks composed of non-toxic building blocks. Makromol Chem Rapid Commun 9: 589594.

Bruin P, Smedinga J, Pennings, AJ, Jonkman MF (1990) Biodegradable lysine diisocyanate-based poly(glycolide-co- $\varepsilon$-caprolactone)-urethane network in artificial skin. Biomaterials 11: 191-295.

Burg KJL, Porter S, Kellam JF (2000) Biomaterials development for bone tissue engineering. Biomaterials 21: 2347-2359.

Burkoth AK, Anseth KS (2000) A review of photocrosslinked polyanhydrides: in situ forming degradable networks. Biomaterials 21: 2395-2404.

Chu CC (1981a) An in-vitro study of the effect of buffer on the degradation of poly(glycolic acid) sutures. J Biomed Mater Res 15: 19-27.

Chu CC (1981b) The in-vitro degradation of poly(glycolic acid) sutures- effect of $\mathrm{pH}$. J Biomed Mater Res 15: 795-804.

Chu CC (1981c) Hydrolytic degradation of polyglycolic acid: tensile strength and crystallinity study. J Appl Polym Sci 26: 1727-1734.

Cutright D, Beasley J, Perez B (1971) Histologic comparison of polylactic acid sutures. Oral Surg 32: 165-173.

De Groot JH, Nijenhuis AJ, Bruin P, Pennings AJ, Veth RPH, Klompmaker J, Jansen HWB (1990) Use of porous biodegradable polymer implants in meniscus reconstruction. 1. preparation of porous biodegradable polyurethanes for the reconstruction of meniscus lesions. Colloid Polymer Sci 268: 1073-1081.

De Groot JH, De Vrijer R, Pennings AJ, Klompmaker J, Veth RPH, Jansen HWB (1996) Use of porous polyurethanes for meniscal reconstruction and meniscal prosthses Biomaterials. 17: 163-173.

Domb AJ (1989) Poly(propylene glycol fumarate) compositions for biomedical applications. United States Patent 4888 413: 1-31.

Domb AJ, Langer R (1987) Polyanhydrides I: Preparation of high molecular weight polyanhydrides. J Polym Sci, Part A, Polymer Chem 25: 3373-3386.

Frazier DD, Lathi VK, Gerhart TN, Hayes WC (1997) Ex vivo degradation of a poly(propylene glycol-fumarate) biodegradable particulate composite bone cement. J 
Biomed Mater Res 35: 383-389.

Gabelnick HL (1983) Long acting steroid contraception. In: Advances in Human Fertility and Reproductive Endocrinology. Mishell Jr DR, ed. Raven Press, New York. Vol 3, pp. 149-173

Gerhart TN, Hayes WC (1989) Bioerodible implant composition. United States Patent 4843 112: 1-16.

Gibbons DF (1992) Tissue response to resorbable synthetic polymers. In: Degradation Phenomena on Polymeric Biomaterials. Plank H, Dauner M Renardy M, eds. Springer Verlag, New York. pp 97-104.

Gilding DK (1981) In: Biodegradable Polymers. Biocompatibility of Clinical Implant Materials Vol II. Williams DF, ed. CRC Press, Boca Raton, FL. Vol 2, pp 209-232.

Gilding DK, Reed AM (1979) Biodegradable polymers for use in surgery-polyglycolic/poly(acetic acid) homo- and copolymers: 1 . Polymer 20: 1459-1464.

Gogolewski S, Pennings AJ (1982) Biodegradable materials of polylactides, 4 Porous biomedical materials based on mixtures of polylactides and polyurethanes. Makromol Chem Rapid Commun 3: 839-845.

Gogolewski S, Pennings AJ (1983) An artificial skin based on biodegradable mixtures of polylactides and polyurethanes for full-thickness skin wound covering. Makromol Chem Rapid Commun 4: 675-680.

Gunatillake PA, Meijs GF, McCarthy SJ (2001) Developments in design and synthesis of biostable polyurethanes. In: Biomedical Applications of Polyurethanes. Vermette P, Griesser HJ, Laroche, G, Guidoin R, eds. Landes Bioscience, Georgetown. pp 160-170.

Hayashi T (1994). Biodegradable polymers for biomedical applications. Prog Polymer Sci 19: 663-702.

Heller J, Barr J, Ng SY, Shen H-R, SchwachAbdellaoui K, Gurny R, Vivien-Castioni N, Loup PJ, Baehni P, Mombelli A (2002). Development and applications of injectable poly(ortho esters) for pain control and periodontal treatment. Biomaterials 23: 4397-4404.

Hirt TD, Neuenschwander P, Suter UW (1996) Synthesis of degradable, biocompatible, and tough blockcopolyesterurethanes. Macromol Chem Phys 197: 4253 4268.

Hofmann GO (1995) Biodegradable implants in traumatology: A review on the state-of-the-art. Arch Orthop Trauma Surg 114: 123-132.

Holland SJ, Tighe BJ (1992) Biodegradable polymers. In: Advances in Pharmaceutical Science. Academic Press, London. Vol 6, pp 101-164.

Hollinger JO (1983) Preliminary report on osteogenic potential of a biodegradable copolymer of polylactide (PLA) and polyglycolide (PGA). J Biomed Mater Res 17: 71-82.

Hollinger JO, Jamiolkoski DD, Shalaby SW (1997) Bone repair and a unique class of bidegradable polymers: The polyesters. In: Biomedical Applications of Synthetic Biodegradable Polymers. Hollinger JO, ed. CRC Press, Boca Raton, FL. pp 197-222.

Hubbell J (1995) Biomaterials in tissue engineering. Biotechnology 13: 565-576.

In'tVeld PJA, Velner EM, Van DeWhite P, Hamhuis J,
Dijkstra PJ, Feijen J (1997) Melt block copolymerisation of e-caprolactone and L-Lactide. J. Polym Sci Part 1 Polymer Chem 35: 219-226.

Jen AC, Peter SJ, Mikos AG (1999) Preparation and use of porous poly(a-hydroxyester scaffolds for bone tissue engineering. In: Tissue Engineering Methods and Protocols. Morhgan JR, Yarmush ML eds Humana Press, Totowa. pp 133-140.

Kharas GB, Kamenetsky M, Simantirakis J, Beinlich KC, Rizzo AT, Caywood GA, Watson K (1997) Synthesis and characterization of fumarate-based polyester for use in bioresorbable bone cement composites. J Appl Polymer Sci 66: 1123-1137.

Kohn J, Langer R (1997) Bioresorbable and bioerodible materials. In: An Introduction to Materials in Medicine. Ratner BD, Hoffman AS, Schoen FJ, Lemon JE, eds. Academic Press, San Diego. pp 65-73.

Kronenthal RL (1975) Biodegradable polymers in medicine and surgery. Polymer Sci Technol 8: 119-137.

Kulkarni RK, Pani KC, Neuman C, Leonard F(1966) Polylactic acid for surgical implants. Arch Surg 93: 839843.

Lamba NMK, Woodhouse KA, Cooper SL (1998) Polyurethanes in Biomedical Applications. CRC Press: New York p 205-241.

Laurencin CT, Peirrie-Jacques HM, Langer R (1990) Toxicology and biocompatibility considerations in the evaluation of polymeric materials for biomedical applications. Clin Lab Med 10: 549-570.

Laurencin CT, Maria EN, Elgendy HM, El-Amin SF, Allcock HR, Pucher SW, Ambrosio AA(1993) Use of polyphosphazenes for skeletal tissue regeneration. J Biomed Mater Res 27: 963-973.

Laurencin, CT, El-Amin SF, Ibim, SE, Willoughby DA, Attawia M, Allcock HR, Ambrosio AA (1996) A highly porous 3-dimentional polyphophazene polymer matrix for skeletal tissue regeneration. J Biomed Mater Res 30: 133-138.

Leong KW, Brott BC, Langer R (1985) Bioerodible polyanhydrides as drug-carrier matrices. I: Characterization, degradation, and release characteristics. J Biomed Mater Res 19: 941-955.

Mark JE, Alcock HR, West R (1992) Inorganic Polymers. Prentice Hall, Upper Saddle River, NJ. Chapter 3.

Mayer MH, Hollinger JO (1995) Biodegradable bone fixation devices. In: Biomedical Applications of Synthetic Biodegradable Polymers. Hollinger JO, ed. CRC Press, Boca Raton, FL. pp 173-195.

McGill DB, Motto JD (1974) An industrial outbreak of toxic hepatitis due to methylenedianiline. New Engl J Med 291: 278-282.

Middleton JC, Tipton AJ (2000) Synthetic biodegradable polymers as orthopaedic devices. Biomaterials 21: 23352346.

Mikos AG, Temenoff JS (2000) Formation of highly porous biodegradable scaffolds for tissue engineering. EJB Electron J Biotechnol 3: 114-119 (available on http:// www.ejb.org/content/vol3/issue2/full/5).

Miller RA, Brady JM, Cutright DE (1977) Degradation rates of oral resorbable implants (polylactates and 
polyglycolates): rate modification with changes in PLA/ PGA copolymer ratios. J Biomed Mater Res 11: 711-719.

Muggli DS, Burkoth AK, Keyser SA, Lee HR, Anseth KS (1998) Reaction behaviour of biodegradable, photo cross-linkable polyanhydrides. Macromolecules 31: 41204125 .

Nelson JF, Stanford HG, Cutright DE (1977) Evaluation and comparison of biodegradable substances as osteogenic agents. Oral Surg 43: 836-843.

Ng SY, Vandamme T, Tayler MS, Heller J (1997) Synthesis and erosion studies of self-catalysed poly(orthoester)s. Macromolecules 30: 770-772.

Peter SJ, Miller MJ, Yaszemski MJ, Mikos AG (1997a) Poly(propylene fumarate). In: Handbook of Biodegradable Polymers. Domb AJ, Kost J, Wiseman DM eds. Harwood Academic Publishers, Amsterdam. pp 87-98.

Peter SJ, Nolley JA, Widmer MS, Merwin JE, Yazemski MJ, Yasko AW, Engel PS, Mikos AG (1997b) In vitro degradation of a poly(propylene fumarate)/ 3 tricalcium phosphate composition orthopaedic scaffold. Tissue Eng 3: 207-215.

Peter SJ, Miller ST, Zhu G, Yasko AW, Mikos AG (1998a) In vivo degradation of a poly(propylene fumarate)/\$-tricalcium phosphate injectable composite scaffold. J Biomed Mater Res 41: 1-7.

Peter SJ, Miller MJ, Yasko AW, Yaszemski MJ, Mikos AG (1998b) Polymer concepts in tissue engineering. J Biomed Mater Res (Appl Biomater) 43: 422-427.

Peter SJ, Suggs AJ, Yazemski MJ, Engle PS, Mikos AG (1999) Synthesis of poly(propylene fumarate) by acylation of propylene glycol in the presence of a proton scavenger. J Biomater Sci Polym Edn 10: 363-373.

Pitt CG, Marks TA, Schindler A. (1981) Naltrexone. Willette RE, Barnet G, eds National Institute on Drug Abuse Research Monograph. 28: 232-253.

Pinchuk L (1994) A review of the biostability and carcinogenicity of polyurethanes in medicine and the new generation of 'biostable polyurethanes. J Biomater Sci Polymer Edn 6: 225-267.

Pulapura S, Kohn J (1992) Tyrosine derived polycarbonates: backbone modified "pseudo-poly(amino acids) designed for biomedical applications. Biopolymers 32: 411-417.

Qui LY, Zhu KJ (2000). Novel biodegrable polyphosphazenes containing glycine ethyl ester and benzyl ester of amino acethydroxamic acid as cosubsituents: synthesis, characterization and degradation properties. J Appl Polym Sci 77: 2987-2955.

Reed AM, Gilding DK (1981) Biodegradable polymers for use surgery-poly(glycolic)/polylactic acid) homeo and copolymers 2 . In-vitro degradation. Polymer 22: 494504.

Sawhney AS, Drumheller PD (1998) Polymer synthesis. In: Frontiers in Tissue Engineering. Patrick CW, Mikos AG, McIntire LV, eds. Pergamon, New York. pp 83-106.

Saad B, Hirt TD, Welti M, Uhlschmid GK, Neuenschwander P, Suter UW (1997) Development of degradable polyesterurethanes for medical applications: In vitro and in vivo evaluation. J Biomed Mater Res 36: 65-
74.

Sanderson JE (1988) Bone replacement and repair putty material from unsaturated polyester resin and vinyl pyrolidone. United States Patent 4,722948: 1-14.

Schakenraad JM, Nieuwenhues P, Molenaar I, Helder J, Dykstra PJ, Feijen J (1989) In-vivo and in-vitro degradation of glycine/DL-lactic acid copolymers. J Biomed Mater Res 23: 1271-1288.

Seidel JO, Uhrich KE, Laurencin CT, Langer R (1996). Erosion of poly(anhydride-co-imides): A preliminary mechanistic study. J Appl Polym Sci 62: 1277-1283.

Shalaby SW (1988) Bioabsorbable Polymers. In: Encyclopedia of Pharmceutical Technology. Swarbrick J, Boylan JC, eds. vol 1, pp 465-476.

Skarja GA, Woodhouse. KA (1998) Synthesis and characterization of degradable polyurethane elastomers containing an amino acid-based chain extender. J Biomater Sci Polym Ed 9: 271-295.

Skarja GA, Woodhouse KA (2000) Structure-property relationships of degradable polyurethane elastomers containing an amino acid-based chain extender. J Appl Polymer Sci 75: 1522-1534.

Spaans CJ, Belgraver VW, Rienstra O, De Groot JH, Veth RPH, Pennings AJ(2000) Solvent-free fabrication of micro-porus polyurethane amide and polyurethane-urea scaffolds for repair and replacement of the knee-joint meniscus. Biomaterials 21: 2453-2460.

Storey RF, Taylor AE (1998). Effect of stannous octoate on the composition, molecular weight, and molecular weight distribution of ethyleneglycol-initiated poly(ecaprolactone). J Macromol Sci- Pure Appl Chem A35: 723-750.

Storey RF, Wiggins JS, Mauritz KA, Puckett AD (1993) Bioabsorbable composites. II: Nontoxic, L-lysinebased (polyester-urethane) matrix composites. Polymer Composites 14: 17.

Storey RF, Wiggins JS, Puckett AD (1994) Hydrolyzable poly(ester-urethane) networks from 1-lysine diisocyanate and d,l-lactide/e-caprolactone homo and copolyester triols. J Polymer Sci: Part A: Polymer Chemistry 32: 2345-2363.

Tangpasuthadol V, Pendharkar SM, Kohn J (2000a) Hydrolytic degradation of tyrosine-derived polycarbonates, a class of new biomaterials. Part I: Study of model compounds. Biomaterials 21: 2371-2378.

Tangpasuthadol V, Pendharkar SM, Peterson RC, Kohn J (2000b) Hydrolytic degradation of tyrosine-derived polycarbonates, a class of new biomaterials. Part II: Study of model compounds. Biomaterials 21: 2379-2387.

Tayler MS, Daniels AU, Andriano KP, Heller J (1994) Six bioabsorbale polymers: In-vitro acute toxicity of accumulated degradation products. J Appl Biomater 5: 151157.

Temenoff JS, Mikos AG (2000) Injectable biodegradable materials for orthopaedic tissue engineering. Biomaterials 21: 2405-2412.

Thomson RC, Wake MC, Yaszemski, Mikos AG (1995a) Biodegradable polymer scaffolds to regenerate organs. Adv Polymer Sci 122: 245-274.

Thomson RC, Wake MC, Yaszemski MJ, Mikos AG 
(1995b) Biodegradable polymer scaffolds to engineer trabecular bone. J Biomater Sci Polymer Ed 7: 23-38.

Uhrich KE, Gupta A, Thomas TT, Laurencin C, Langer R (1995) Synthesis and characterization of degradable polyanhydrides. Macromolecule 28: 2148-2193.

Uhrich KE, Thomas TT, Laurencin CT, Langer R (1997) In vitro degradation characteristics of poly(anhydride-imide) containing trimellitylimidoglycine. J Appl Polymer Sci 63: 1401-1411.

VanSliedregt A, vanBlitterswijk CA, Hesseling SC, Grote JJ, deGroot K (1990) The effect of the molecular weight of polylactic acid on in-vio biocompatibility. Adv Biomaterials 9: 207-212.

VanSliedregt A, Radder AM, deGroot K, Van Blitterswijk CA (1992) In-vitro biocompatibility testing of polylactides Part I: Proliferation of different cell types. J Mater Sci: Mater Med 3: 365-370.

Verheyen CCPM, deWijn JR, VanBlitterswijk CA, Rozing PM, deGroot K (1993) Examination of efferent lymph nodes after 2 years of transcortical implantation of poly(L-lactide) containing plugs: a case report. J Biomed Mater Res 27: 1115-1118.

Vert M, Christel P, Chabot F, Leray J. Hastings GW, Ducheyne P, eds. (1984) Macromolecular Biomaterials. CRC Press, Boca Raton. pp 119-142.

William DF, Mort E (1977) Enzyme-accelerated hydrolysis of polyglycolic acid. J Bioeng 1: 231-238.

Wong WH, Mooney DJ (1997) Synthesis and properties of biodegradable polymers used as synthetic matrices for tissue engineering. In: Synthetic Biodegradable Polymer Scaffolds. Atala A, Mooney D, eds. Burkhäuser, Boston. pp 51-84.

Yaszemski MJ, Mikos Ag, Payne RG, Hayes WC (1994) Biodegradable polymer composites for temporary replacement of trabecular bone: The effect of polymer molecular weight on composite strength and modulus. Mat Res Symp Proc 331: 251-255.

Yazemski MJ, Payne RG, Hayes WC, Langer R, Mikos AG (1996) Evolution of bone transplantation: molecular, cellular and tissue strategies to engineer human bone. Biomaterials 17: 175-185.

Zang JY, Beckman EJ, Piesco NP, Agrawal S (2000) A new peptide-based urethane polymer: synthesis, biodegradation, and potential to support cell growth in-vitro.
Biomaterials 21: 1247-1258.

Zdrahala RJ, Zdrahala IJ (1999) Biomedical applications of polyurethanes: a review of past promises, present realities, and a vibrant future. J Biomater Appl 14: 67-90.

\section{Discussion with Reviewer:}

N. Gadegaard: Will the catalysts used for the polymerisation cause problems in vivo?

Authors: The most common catalysts used in preparing polylactides and glycolides are organotin compounds and an example is stannous octoate. This catalyst is also used widely for making polyurethanes. There are some reports on the toxicity of stannous octoate related to breast implant safety evaluations (Bondurant et al., 2000). One study reports no toxic or carcinogenic effects in a 22 month invivo study in rats. Polyurethanes polymerized using stannous octoate have also been used in other medical implants. Examples includes cardiac pace makers using Pellethane as lead insulation. We have also come across references which state that stannous octoate is accepted by FDA as a food additive (Gilding and Reed, 1979, text reference; Kim et al., 1992)

In most cases the polymerisation catalysts or initiator residues are extremely difficult to remove from the final polymer, and accordingly they are left to stay with the polymer.

Camphorquinone type initiators used in in-situ curable polymer compositions have also been used in curing dental fillings. Unlike catalysts, radical initiators are incorporated into the polymer structure with some residues remaining as low molecular weight compounds in the final polymer.

\section{Additional References}

Bondurant S, Ernster V, Herdman R (2000) Silicone Toxicology. In: Safety of Silicon Breast Implants. Bondurant S, Ernster V, Herdman R, eds. The National Academic Press, Washington, DC. pp 80-113

Kim SY, Han YK, Kim YK, Hong SI (1992) Multifunctional initiation of lactide polymerization by stannous octoate/pentaerythritol. Makromol Chem 193: 1623-1631. 